\title{
IDENTIFICATION OF CRITICAL GROUND MOTIONS FOR SEISMIC PERFORMACE ASSESSMENT OF STRUCTURES
}

\author{
Rajesh P. Dhakal ${ }^{1 *}$, John B. Mander ${ }^{1}$ and Naoto Mashiko ${ }^{1}$ \\ ${ }^{1}$ Department of Civil Engineering, University of Canterbury, Private bag 4800, Christchurch \\ 8020, New Zealand \\ *Corresponding author: Ph: +64-3-3642987 ext 7673; Fax: +64-3-3642578; \\ E-mail: rajesh.dhakal@canterbury.ac.nz
}

\section{Summary}

A method is established to identify critical earthquake ground motions that are to be used in physical testing or subsequent advanced computational studies to enable seismic performance to be assessed. The ground motion identification procedure consists of: choosing a suitable suite of ground motions and an appropriate intensity measure; selecting a computational tool and modelling the structure accordingly; performing Incremental Dynamic Analysis on a nonlinear model of the structure; interpreting these results into $50^{\text {th }}$ (median) and $90^{\text {th }}$ percentile performance bounds; and identifying the critical ground motions that are close to these defining probabilistic curves at ground motion intensities corresponding to the design basis earthquake and the maximum considered earthquake. An illustrative example of the procedure is given for a reinforced concrete highway bridge pier designed to New Zealand specifications. Pseudodynamic tests and finite element based time history analyses are performed on the pier using three earthquake ground motions identified as: (i) a Design Basis Earthquake (10\% probability in 50 years) with 90 percent confidence of non-exceedance; (ii) a Maximum Considered Event (2\% probability in 50 years) representing a median response; and (iii) a Maximum Considered Event representing 90 percent confidence of non-exceedance.

\section{Keywords}

Performance Based Earthquake Engineering (PBEE), Seismic performance assessment, Pseudodynamic test, Critical ground motions, Incremental Dynamic Analysis (IDA), Confidence bounds, Time-history analysis, Design Basis Earthquake (DBE), Maximum Considered Earthquake (MCE)

\section{Introduction}

In Performance Based Earthquake Engineering (PBEE), seismic design is carried out through an iterative loop comprising the following four steps: (i) design the structure and detail it accordingly to satisfy prescribed performance requirements; (ii) assess the seismic performance of the designed structure; (iii) compare the expected performance against the prescribed requirements; and (iv) decide on the appropriateness of the designed structure. The second step; i.e. assessing the seismic performance; can be performed either through numerical analysis of the structure subjected to the design actions using an appropriate computational tool or by testing a scaled model of the structure or its components in the laboratory. Although physical tests are time and resource consuming, performance assessment by experimental means has its own merits. For example, an experimental approach avoids the assumptions/idealizations pertinent to the analytical modelling and it gives the most realistic indication of expected structural performance.

In order to experimentally assess the seismic performance of structures, the applied loading/action to which the physical structural model is to be subjected to needs to be decided 
in advance. Historically, in customary experimental practice, gradually increasing reversed cyclic displacements are applied to the specimen (i.e. scaled physical model) until adverse performance or collapse is observed. The results are then used to infer the likely performance of the prototype structure when exposed to design basis and/or extreme earthquakes. Such quasi-static loading protocols have also been specified in various specifications/standards [13]. Nevertheless, such controlled and patterned displacement cycles are markedly different from the actual response of structures to earthquakes which consist of irregular and random displacement reversals. Hence, the results of quasi-static displacement-regulated tests may not always accurately represent the structure's seismic performance. Studies [4-5] have also shown that the loading path affects structural response.

To assess the performance of structures to an earthquake, the earthquake ground motion needs to be applied directly to the physical model of the structure. This is commonly accomplished in one of two ways: (i) either through a pseudodynamic test on a near full scale subassemblage; or (ii) a shaking table test on a reduced scale model. In pseudodynamic tests, for each time step of a given ground motion record displacement response of a structure is calculated based on the measured real time structural stiffness, and the obtained displacement is applied to the structural model [6-8]. On the other hand, in shaking table tests the earthquake ground acceleration records are directly applied to the table on which the scaled physical model of the structure is fixed.

In seismic design codes, the standard earthquake ground motions to be used in performance based seismic design of structures in a given location are prescribed in terms of their probability of occurrence, which is established based on a uniform hazard (statistical) analysis of past earthquakes in that region. For example, the Design Basis Earthquake (DBE) usually refers to a $10 \%$ recurrence probability in 50 years; (return period of 475 years), and the Maximum Considered Earthquake (MCE) has a recurrence probability of 2\% in 50 years (return period of 2450 years). For seismic design, most codes and standards specify seismic hazard in terms of a single intensity measure such as the Peak Ground Acceleration (PGA) or a spectral ordinate at a given period. Codes and standards generally remain silent on other important aspects of seismic hazard, such as the frequency content, duration and effective number of loading cycles. Different ground motion records with the same PGA do not induce the same level of response and also do not cause the same extent of damage on a structure [9]. Hence, the test results obtained by using one ground motion record may not provide sufficient confidence that the structure, if subjected to another ground motion record with the same PGA, will yield similar response.

Given the increased use of pseudodynamic and shaking table tests, it is considered timely to propose a methodology that has a degree of formalism in ground motion selection for experimental use. The principal purpose is to select records that give the user a measurable degree of confidence in their use. That is, there is a prescribed probability of not exceeding a certain level of adverse performance when any earthquake of similar intensity strikes. This paper establishes a methodology to identify these critical ground motion records based on a thorough analytical investigation. To illustrate the proposed procedure, ground motion records that induce $90^{\text {th }}$ percentile response as a DBE $(\mathrm{PGA}=0.4 \mathrm{~g})$, and $50^{\text {th }}$ and $90^{\text {th }}$ percentile responses as an $\mathrm{MCE}(\mathrm{PGA}=0.8 \mathrm{~g})$ respectively for a typical bridge pier are identified in this paper. In order to justify the suitability of the identified ground motions, these records are then applied in sequence to the bridge pier in nonlinear time-history dynamic analysis and the responses are compared. A one-off pseudodynamic test is also conducted on a scaled model of the pier with these three records arranged sequentially to highlight the application of the identified records in the experimental assessment of structural seismic performance. 


\section{Major steps in Critical Ground Motions Identification}

\section{Collection of ground motion records to be investigated}

It is a common practice to scale any available ground motion data recorded during an earthquake to a desired intensity measure such as PGA and use the generated ground motion in seismic tests. Although nowadays there are plenty of ground motion records available, no clear basis exists by which researchers could choose one record over another for an experimental investigation. In order to establish guidelines on this issue, structural responses to different ground motion records available need to be qualitatively compared. Hence, a number of common ground motion records are needed for comparison. Wherever possible, the collected ground motion records should be from the same region or a region geologically similar to where the structure is to be built. The soil condition where the collected ground motions were recorded should also resemble, as closely as possible, the soil condition of the design locality. More importantly, the distance from the nearby faults and tectonic plate boundaries to the construction site should also be taken into account while collecting the ground motion records. For example, near source earthquake records should be used if the designed structure is to be built very close to an active fault.

\section{Selection of computational tool and modelling the structure}

As the response of the structure to be tested to the collected ground motion records need to be compared, a finite element analysis tool capable of performing nonlinear timehistory dynamic analysis is needed. An analytical model of the structure should be developed and the ground motion records collected in the previous step should be expressed in an appropriate format according to the needs of the computational tools to be used. As the comparison of structural response would be done mainly to rank the severity of the earthquakes and the absolute values of the responses obtained from the analysis will not be used in design, reasonable approximation in the analytical approach aiming to simplify the process is acceptable. Nevertheless, these analytical simplifications should not affect the major mechanisms contributing significantly to the dynamic response of the analysed structure. For example, using linear model for dynamic analysis and using single-degree of freedom representation for multistorey buildings that may have significant contribution from higher modes are not appropriate.

\section{Performing Incremental Dynamic Analysis}

Incremental Dynamic Analysis (IDA) [10] involves performing nonlinear dynamic time-history analyses of a prototype structural system under a suite of ground motion records, each scaled to several intensity levels designed to force the structure all the way from elastic response to final global dynamic instability (collapse). IDA is a new methodology developed to estimate structural performance under seismic loads which can give a clear indication of the relationship between the seismic capacity and the demand. Engineers can estimate principal engineering demand parameter (EDP) representing critical response measure such as maximum drift or displacement for a given intensity measure (IM) given by PGA or spectral acceleration amplitude of the ground motion records. The need to identify a critical ground motion for the purpose of an experimental investigation or further advanced analysis and design can also be accommodated by the application of IDA.

Once the ground motion records, the computational tool and the analytical model of the structure have been established, IDA should be performed. To start the analysis, the 
collected ground motion records have to be scaled from a low intensity measure to several higher levels of intensity measures. For each increment of the intensity measure, a nonlinear dynamic time-history analysis is performed. Analyses are repeated for higher intensity measures until analysis cannot proceed further due to numerical instability; that is structural collapse occurs. Locating the maximum value of the chosen engineering demand parameter observed in an analysis gives one point in the intensity measure versus demand parameter (IM vs. EDP) plot. Connecting the data points obtained from each analysis for a given ground motion record with different intensity measures gives the IDA curve for that ground motion. This process should then be repeated for all ground motions collected in step 1 to generate a set of IDA curves.

A synthesis of IDA curves into various percentile bands should then be performed. Bands of particular significance include the $50^{\text {th }}$ percentile (median), and $90^{\text {th }}$ percentile; the latter being commonly accepted nowadays as an upper limit for performance based earthquake engineering acceptance criteria [11-13]. These bounds help the designer to single out critical ground motions which can then be used in physical testing or advanced computational study to investigate the damage outcomes on a structure with a certain level of confidence.

\section{Identifying critical ground motions based on the IDA curves}

The final task is to scrutinize the IDA curves and to answer the following question: Which ground motion from the collected suite of eligible candidate records should be adopted for carrying out seismic performance assessment of the structure? Results from the foregoing IDA analyses along with the desired outcomes of the experimental or analytical investigation to be subsequently carried out can be used as a basis for choosing the critical ground motions. In order to obtain the ground motion records to be used for assessing structural performance to a seismic hazard level (either DBE or MCE), the variability of the engineering demand parameter for the intensity measure corresponding to the prescribed hazard level should be represented by a lognormal distribution.

In performance based design, a designer invariably wants to ensure that the designed structure is not severely damaged when subjected to a DBE, meaning that the chosen ground motion should give almost full (say 90\%) confidence that the structural response and damage due to a DBE would not exceed those induced by the selected ground motion. Similarly, the designed structure should not collapse when subjected to an MCE. Normal structures may be permitted to incur significant damage when subjected to an MCE. Nevertheless, if the structure to be designed is very important and needs to be used shortly after an earthquake, a designer would normally want to ensure that it is not severely damaged even in an MCE. It is therefore suggested that two records should be selected to represent MCE so that the results obtained using these two records give median (50\%) and almost full (say 90\%) confidence of not being exceeded in the rare event of the MCE. First, it is suggested that the record representing $90^{\text {th }}$ percentile response for an intensity level that coincides with the DBE be chosen. Next, the record representing median response for the intensity level of an MCE should be selected and, finally, the record representing $90^{\text {th }}$ percentile MCE response be selected and used as a basis for final destructive testing. The critical ground motions at the DBE and MCE levels may not necessarily be the same.

To be roughly $50 \%$ and $90 \%$ confident about the experimental outcomes, one should closely examine the ground motion records that fall within the 45 to 55 and 85 to 95 percentile range, respectively. If several records fall in the required range and it is difficult to select one of them based on logic, then the results of the time-history dynamic analyses using these short-listed records may need to be closely scrutinised. Factors other than the chosen 
response parameter that might influence failure (e.g. cyclic loading effect that could potentially lead to a low cycle fatigue failure; amplifications of overturning/rocking effects by large axial load; amplification of pier moments arising from higher mode effects; bidirectional and torsional motion response) may be evaluated and compared before adopting the critical ground motions for experimental application.

\section{Example: Critical Ground motions for Seismic Performance Assessment of a Bridge Pier}

\section{Details of the bridge pier design}

The generic methodology described above will now be applied to identify the ground motion records to be used in seismic performance assessment of a reinforced concrete bridge pier. The bridge pier selected for this example is designed using the seismic design standard of New Zealand [14]. The pier is $7 \mathrm{~m}$ high and is taken from a "long" multi-span highway bridge on firm soil with a $40 \mathrm{~m}$ longitudinal span and a $10 \mathrm{~m}$ transverse width. The weight of the super-structure to be supported by the pier is calculated to be $7,000 \mathrm{kN}$. The bridge is considered to be located in a high seismic zone in New Zealand with the PGA of the DBE being $0.4 \mathrm{~g}$. The elevation views of the whole bridge and the pier along with the design parameters of the pier are illustrated in Figure 1.

\section{Collection of seismic ground motion records}

Although New Zealand is a seismically active country, fortunately not many big earthquakes have occurred in New Zealand in the recent past, thereby creating a scarcity of regional seismic ground motion records. New Zealand has the Alpine fault passing longitudinally almost through the middle of the country and many cities in New Zealand fall as close as a few kilometres from this fault. To represent a location in New Zealand, earthquakes recorded at moderate distances from the source are needed. Vamvatsikos and Cornell [10] used twenty ground motion records to analyse mid-rise buildings in order to provide sufficient accuracy of seismic demands. These earthquakes have magnitudes in the range of 6.5-6.9 with moderate epi-central distances mostly in the range of 16 to $32 \mathrm{~km}$; all these ground motions were recorded on firm soil. The same suite of ground motion records is adopted in this example. These ground motion records are listed in Table 1.

Figure 2 (a) shows the response spectra for each of the 20 earthquake records scaled to the intensity measure of $\mathrm{DBE}$ in the design location (i.e. $\mathrm{PGA}=0.4 \mathrm{~g}$ in this example). Figure 2 (b) presents a plot of the lognormal standard deviation $\beta_{D}$ across the spectrum which is sometimes referred to as the dispersion and is approximately equal to the coefficient of variation [12]. As expected, a significant degree of record-to-record randomness (i.e. aleotoric variability) is evident with respect to the median spectral curve, indicating that different earthquakes with the same PGA may extract significantly different response out of a structure. Note that the earthquakes shown in the list are all recorded in the United States, and earthquakes recorded elsewhere on firm soils and at a moderate distance from the source could easily be added to the list. It will surely increase the amount of analysis to be done before coming to conclusion, but may not necessarily noticeably enhance the final outcome.

\section{Computational modelling and performing IDA}


In order to perform IDA of the bridge pier, a nonlinear finite element analysis program RUAUMOKO [15] is used in this example. The reinforced concrete circular bridge pier is modelled as a single-degree-of-freedom system and is analysed using a modified Takeda hysteresis model [15]. Using RUAUMOKO, dynamic time-history analyses are carried out for the twenty ground motion records in the suite. The acceleration amplitude of each ground motion record is multiplied by a scaling factor to vary the intensity measure, but the time scale of the ground acceleration record is not altered. Starting from a small scaling factor, the scaling factor is gradually increased until the scaled ground motion causes collapse of the bridge pier. Spectral acceleration is known to serve as a more consistent intensity measure; especially for a simple structure used in this study which is well-represented by a singledegree-of-freedom model [16]. Nevertheless, this study is a component of a project aimed at comparing bi-directional behaviour of bridge piers designed by different national design codes (USA, NZ, Japan), in which PGA was found to be a common measure used to represent seismic hazards. Hence, PGA is used as the intensity measure in this study. The critical response parameter (i.e. the engineering demand parameter) is chosen to be the maximum drift ratio experienced by the pier during the ground motion duration.

The maximum drift incurred by a scaled ground motion with a known PGA gives one point in the intensity measure versus engineering demand parameter (PGA vs. maximum drift in this example) plot and similar points corresponding to different values of PGA for the same earthquake record are joined together to yield the IDA curve for that earthquake. A typical IDA curve (i.e. PGA vs. maximum drift relationship) generated for one earthquake in the suite is presented in Figure 3 (a). Similar curves for the other earthquakes in the suite are also generated through series of dynamic time-history analyses. The generated IDA curves for the 20 earthquakes are plotted together in Figure 3 (b), which also shows the lognormal standard deviation of the maximum drift for different values of PGA. Although the outcomes of different earthquakes vary significantly, the lognormal standard deviation is constant until the PGA becomes high enough to enable some of the earthquakes to cause toppling failure of the pier. It was found that the lognormal standard deviation would decrease by approximately $30 \%$ (both for DBE and MCE) if spectral acceleration was used as the intensity measure. In other words, only 10 (i.e. $20 \times 0.7^{2}$ ) records would be required to obtain the results with the same level of confidence [16].

\section{Identifying critical earthquake ground motions}

Before selection of the critical ground motions, the chosen intensity measure (PGA) corresponding to the DBE and MCE (i.e. seismic hazard levels for performance based seismic design) need to be determined. The PGA of the DBE, which has $10 \%$ probability of exceedance in 50 years (475-year mean return period), is $0.4 \mathrm{~g}$ for the design location in New Zealand. Similarly, the PGA for the MCE, which has $2 \%$ probability of exceedance in 50 years (2450-year mean return period), is assumed to be $0.8 \mathrm{~g}$. For each PGA value, there are 20 (equal to the number of ground motion records collected) different values of the maximum drift, from which a median $\left(50^{\text {th }}\right.$ percentile $)$ and a $90^{\text {th }}$ percentile values of the maximum drift for that PGA level are obtained. When these points corresponding to different PGA levels are connected, the $50^{\text {th }}$ and $90^{\text {th }}$ percentile IDA curves can be generated. Figure 4 (a) shows the $10^{\text {th }}, 50^{\text {th }}$ and $90^{\text {th }}$ curves for the bridge pier generated based on the variability of the twenty IDA curves. The selection of the critical ground motions can be performed by matching the corresponding individual IDA curves of different earthquakes against these fractile curves at the required PGA level. The critical ground motions to be chosen should pass through or very close to the point of intersection of the corresponding percentile IDA curve and the horizontal line at the PGA of the seismic hazard to be represented (i.e. DBE or MCE). 
In Figure 4 (a), one such earthquake record has been identified as EQ13 which tended to be slightly weaker than $90 \%$ of all collected records when scaled at $0.4 \mathrm{~g}$ PGA, but it was the closest to the $90^{\text {th }}$ percentile IDA curve at PGA $=0.4 \mathrm{~g}$. The second earthquake record (EQ4) serves as the MCE and it was chosen because it passed very close to the point of intersection of the $50^{\text {th }}$ percentile IDA curve and the horizontal line at $0.8 \mathrm{~g}$ (PGA of MCE). This record (EQ4) represents the average of the twenty records scaled at PGA $=0.8 \mathrm{~g}$. The third and final earthquake record is to be chosen such that it represents $90^{\text {th }}$ percentile of all records at PGA $=0.8 \mathrm{~g}$. Nevertheless, many records in the suite caused failure of the pier at a PGA level lower than $0.8 \mathrm{~g}$, and hence the $90^{\text {th }}$ percentile ground motion at PGA $=0.8 \mathrm{~g}$ could not be explicitly selected. In this example, EQ17 is chosen to represent the destructive hazard level because it is one of the few earthquakes running very close to the $90^{\text {th }}$ percentile IDA curve.

The three critical ground motions selected by this process are presented in Figure 4 (b). Note that the ground motion records are scaled to yield PGA $=0.4 \mathrm{~g}$ for EQ13, and PGA $=$ $0.8 \mathrm{~g}$ for EQ4 and EQ17, and these records are recommended to be used in seismic performance assessment of the bridge pier. What this means is: If EQ13 is scaled to PGA = $0.4 \mathrm{~g}$ and applied to the pier, there is only a small chance $(\sim 10 \%)$ that the incurred response/damage will be exceeded in a DBE. Similarly, if EQ4 and EQ17 are scaled to PGA $=0.8 \mathrm{~g}$ and applied to the pier, the incurred responses and damages will have respectively about $50 \%$ and $10 \%$ chance of being exceeded in a random MCE.

\section{Computational Verification}

Next, the validity of the procedure is verified qualitatively. Note that the latter two ground motions identified as MCE (EQ4 and EQ17) have the same PGA but are identified to give significantly different confidence (50\% and $90 \%$, respectively) of not being exceeded during a random MCE. In order to convincingly verify the critical ground motions selection process, EQ17 (identified as the MCE with $90 \%$ confidence level) must produce significantly larger response out of the pier and induce more severe damage on the pier than EQ13 (identified as DBE) and EQ4 (50\% MCE) do. Although Figure 4 (a) suggests that EQ4 at PGA $=0.8 \mathrm{~g}$ is expected to induce slightly larger response than EQ13 at PGA $=0.4 \mathrm{~g}$ in this example, the median MCE ground motion chosen by this process in general need not necessarily be significantly more damaging compared to the $90^{\text {th }}$ percentile DBE ground motion. As the DBE with PGA $=0.4 \mathrm{~g}$ was adopted for designing the pier, it is reasonable to think that the pier is very likely to collapse under EQ17, which has a PGA of $0.8 \mathrm{~g}$ and is expected to generate an upper bound response. In order to verify these predictions, a computational investigation is carried out to compare the responses of the pier to the three critical ground motions identified above.

Time-history dynamic analyses of the bridge pier subjected to the three identified ground motions are conducted using the Finite Element Analysis Program RUAUMOKO [15]. The modelling approach and the values of key parameters are presented in Figure 5 (a). The bridge pier is modelled as a single-degree-of-freedom system with the axial load coming from the bridge deck modelled as a lumped mass $(\mathrm{W}=7000 \mathrm{kN})$ at the top of the pier. The modified Takeda hysteresis model [15] as schematically illustrated in Figure 5 (a) is used to represent the force-displacement interrelationship of the beam/column element used for the pier. The macro model properties for the time history analysis (i.e. the yield force and stiffness for the skeleton curve of the modified Takeda model) are determined based on nonlinear moment-curvature based push-over analysis carried out assuming appropriate values for the material strengths. Time-history analyses are conducted separately for the three ground motions. 
The responses of the bridge pier to these three critical ground motions are shown in Figure 5 (b). The figures show the time-history of the response drift and the lateral load vs. drift curves for the three different ground motions. The maximum drift is $1.9 \%$ during the DBE (EQ13) and $2.0 \%$ during the $50^{\text {th }}$ percentile MCE (EQ4). This may seem a very small increase in the response given the fact that the PGA of EQ13 is $0.4 \mathrm{~g}$ whereas that of EQ4 is $0.8 \mathrm{~g}$, but the confidence level these two ground motions impart are significantly different; i.e. EQ13 is one of the strongest records for PGA $=0.4 \mathrm{~g}$ whereas EQ4 represents a median record for PGA $=0.8 \mathrm{~g}$. As can also be observed in Figure 4 (a), the maximum drift (slightly more than $2.0 \%$ ) due to EQ4 at a PGA level of $0.8 \mathrm{~g}$ is larger than the maximum drift (slightly less than $2.0 \%$ ) due to EQ13 at a PGA level of $0.4 \mathrm{~g}$ only by a small margin, which is in agreement with the results of the time-history analysis using these two records. This reinforces the commonly held view that using PGA alone is an insufficient representation of the hazard level.

As expected, the pier collapsed when subjected to the $90^{\text {th }}$ percentile MCE (EQ17). As shown in Figure 5 (b), the analysis stopped due to numerical instability before the acceleration record of EQ17 could be finished, and the maximum drift observed before failure was in excess of $6.0 \%$. The lateral load vs. drift hysteresis curve also suggests that the damage sustained and the energy dissipated during EQ17 was significantly larger than during the previous two records. Hence, it is easy to conclude that EQ17 (identified as $90^{\text {th }}$ percentile MCE) was much more devastating than EQ13 (identified as $90^{\text {th }}$ percentile DBE), and more interestingly than EQ4 (identified as $50^{\text {th }}$ percentile MCE) despite having the same PGA. This qualitatively corroborates that the three identified ground motions give conceptually logical outcomes.

\section{Application: Pseudodynamic test of the Pier}

\section{Experimental Details}

Next, the selected critical ground motions are used in a one-off pseudodynamic test of a scaled model of the bridge pier to obtain more realistic and comprehensive information on the seismic performance of the bridge pier. Figure 6 (a) presents details of the specimen which is a $30 \%$ scaled model of the prototype bridge pier described earlier. The longitudinal and transverse reinforcement ratios provided in the specimen were aimed at keeping the same proportional force capacity as in the prototype. The specimen was constructed in three main parts: (i) the rectangular base block; (ii) the circular column; and (iii) the rectangular head block. The concrete was poured separately for each part.

Figure 6 (b) presents an East-West (E-W) elevation view of the specimen set up in the test apparatus. As the loading applied to the specimen in the pseudodynamic test was bidirectional, a similar view existed in the North-South (N-S) direction as well. The specimen was set in a DARTEC universal testing machine. A constant axial force of $630 \mathrm{kN}$ was applied via ball joints attached to the top and bottom platterns of the specimen. L-shaped loading frames and counterweight baskets were attached to the base block of the specimen in each direction. These were connected by $30 \mathrm{~mm}$ diameter high strength threaded bars. Lateral loads were applied in both the E-W and N-S direction via $800 \mathrm{kN}$ hydraulic actuators that were connected to the specimen's head block and the L-shaped load frames via universal joints. In each lateral loading direction, a $1000 \mathrm{kN}$ capacity load cell was installed in-series with the actuator.

As shown in Figure 7, the three critical ground motions selected earlier (EQ13, EQ4 and

EQ17) are applied in sequence to the pier specimen. Note that the pseudodynamic test was bidirectional and the ground motions recorded in both directions were applied simultaneously to the specimen in the corresponding directions. The ground motion in the direction having the 
higher PGA was scaled to yield the PGA required for the represented hazard level (i.e. $0.4 \mathrm{~g}$ for $\mathrm{DBE}$ and $0.8 \mathrm{~g}$ for $\mathrm{MCE}$ ) and the ground motion recorded in the other direction was also multiplied by the same scaling factor. As shown in Figure 7, the first $20 \mathrm{sec}$ of these three ground motion records were used for the input ground motion since the main shock in these records happens in the first $20 \mathrm{sec}$. These trimmed records were connected together with a 5 sec zero acceleration data between them to enable the measurement of residual drift and natural period under the free vibration condition.

\section{Results and Discussions}

Figure 8 shows the results of the pseudodynamic test in the following order (a) plan view of the bi-directional drift orbit; (b) graphics of load displacement behaviour for the N-S and E-W directions; (c) time history graphs of the drift for the two orthogonal directions; (d) photograph showing bar buckling at a drift of 3.6\%; and (e) photograph at the end of the test showing longitudinal bar fracture due to low cycle fatigue. The response of the specimen only in the E-W direction is explained here as it had larger response than the other (N-S) direction) for all three records. The pier yielded at $5.61 \mathrm{sec}$ during the application of EQ13 (identified as the $90^{\text {th }}$ percentile DBE), and the lateral load and the top drift at yielding were $63.3 \mathrm{kN}$ and $0.30 \%$, respectively. Several horizontal cracks with approximately $150 \mathrm{~mm}$ spacing were observed during EQ13, but these cracks closed after the completion of EQ13 record. The maximum drift and the maximum lateral load measured were $1.65 \%$ at $13.83 \mathrm{sec}$ and $159 \mathrm{kN}$ at $6.24 \mathrm{sec}$ respectively. The residual drift was $0.167 \%$ at the conclusion of EQ13. As the pier exceeded the yield drift with several cracks appearing during the test which closed at the conclusion of the EQ13 record and no spalling was apparent, the damage inflicted on the pier by the record EQ13 with PGA $=0.4 \mathrm{~g}$ (i.e. DBE) was assessed to be in the second damage state (i.e. DS2) according to the Hazus damage classification, as shown in Table 2 [17].

During EQ4 (identified as the $50^{\text {th }}$ percentile MCE), the maximum drift was $2.48 \%$ which was measured at $36.93 \mathrm{sec}$. Several horizontal cracks emerged with a spacing of roughly $50 \mathrm{~mm}$ within the bottom $1 \mathrm{~m}$ of the specimen. The cracking was more intensive than during EQ13 but still the residual crack width was very small (approximately $0.2 \mathrm{~mm}$ ) at the conclusion of the record EQ4. The cover concrete remained intact showing no sign of spalling, and the residual drift was $0.25 \%$. According to the Hazus damage classification (see Table 2), the damage on the pier after the record EQ4 with PGA $=0.8 \mathrm{~g}$ (i.e. MCE) was assessed to be still in DS2, albeit closer to the boundary of DS2 and DS3. Agreeing with the relative standing of these two records (EQ13 and EQ4) in Figure 4 (a), the maximum drift and the residual drift after EQ4 are slightly larger than those after EQ13 and the cracks were slightly wider during EQ4 than during EQ13.

As indicated in Figure 8, the important damage events observed during EQ17 (identified as the $90^{\text {th }}$ percentile MCE) were cover concrete spalling at $63.7 \mathrm{sec}$ with $2.5 \%$ drift and buckling of main bars at $68.4 \mathrm{sec}$ with $3.6 \%$ drift. Subsequently, the first bar fracture occurred at $71.7 \mathrm{sec}$ at a drift of $6.0 \%$. The major degradation of the strength of the bridge pier started at $74.5 \mathrm{sec}$ when the top of the pier was at $6.52 \%$ drift. Then, the lateral strength of the pier showed $20 \%$ reduction (from $78.7 \mathrm{kN}$ to $62.6 \mathrm{kN}$ ), although the drift of the pier increased by $1.75 \%$ (from $6.53 \%$ to $8.27 \%$ ). This load degradation was caused by gradual fracture of the main bars. As collapse appeared imminent, for safety reasons, the test was then terminated before the record of EQ17 could finish. Not surprisingly, the damage experienced by the specimen during EQ17 was classified as DS5 according to the Hazus damage classification shown in Table 2.

As the incurred damage suggests, the selection of these three ground motions (EQ13, EQ4 and EQ17) to represent three hazards of increasing severity is appropriate. The fact that 
EQ17 (identified as the $90^{\text {th }}$ percentile MCE) caused the specimen's collapse whereas EQ4 (identified as the $50^{\text {th }}$ percentile MCE), in spite of having the same PGA, could only cause minor damage to the specimen further reinforces the reliability of the proposed ground motion identification process. Note that the difference between the two ground motions representing the $50^{\text {th }}$ and $90^{\text {th }}$ percentile MCE would be smaller if spectral acceleration was used as the intensity measure instead of PGA.

The test results are plotted together with the percentile IDA curves in Figure 9. As can be seen in the figure, the test results (shown by the solid dots) lie very close to the identified ground motions at the corresponding PGA levels except for EQ17. It again justifies the use of the $50^{\text {th }}$ and $90^{\text {th }}$ percentile IDA curves to identify the critical ground motions. Both the analysis and test terminated before the complete record of EQ17 could be applied and the maximum drifts recorded before the termination was $8 \%$ in both cases. Nevertheless, $8 \%$ does not represent the actual response of the pier to EQ17, which could have been significantly higher had the test and analysis been continued for the whole record. Hence, the dots representing the pier's response to EQ17 are indicated with an arrow towards the right in Figure 9 , bringing it closer to the $90^{\text {th }}$ percentile IDA curve at PGA $=0.8 \mathrm{~g}$.

Identifying the three ground motions with increasing order of severity also enabled a one-off test to be conducted to investigate the performance of the pier to these three different seismic hazard levels. If the test was conducted with randomly selected ground motions with PGA of $0.4 \mathrm{~g}$ and $0.8 \mathrm{~g}$, the results would have little use in performance based seismic design. For example, if EQ4 scaled to PGA $=0.4 \mathrm{~g}$ was chosen for a test in which if the pier had remained intact, the result would not have ensured that the pier would be safe in any other DBE of the same intensity as Figure 4 (a) suggests that many other records from the collected suite scaled to $\mathrm{PGA}=0.4 \mathrm{~g}$ would induce significantly larger response. Hence, identifying the critical ground motions to represent different seismic hazard levels is important for seismic performance assessment.

\section{Comparison between Experimental and Analytical Results}

In this section, the experimental seismic performance of the bridge pier is compared with the response predicted by dynamic time-history nonlinear analysis. In order to perform multi-level performance assessment using a single specimen (i.e. to save the resources), the pseudodynamic test was carried out with the three ground motions applied sequentially. On the other hand, the time-history analyses were conducted for each ground motion separately to simulate more realistically the actual situation by exposing the virgin structure to different hazard scenarios. Obviously, some difference in the two results is expected. Although ground motions in both directions were applied to the pier in the 3D nonlinear finite element analysis to simulate the test, results are discussed hereafter only for the major direction. The comparison between the analysis and test results is graphically presented in Figure 10 in the form of (1) hysteresis load-displacement curves and (2) time-history of the drift for the three ground motions.

From the hysteresis curves, it is evident that the shape of the loops obtained from the test had smoother transitions compared to those obtained from analysis. This is partially due to the multilinear nature of Takeda hysteresis model adopted in the analysis, and partly due to the simultaneous bi-directional interaction effect [18], which was not captured by the analytical model used. The time-history of the drift shows good agreement between the

analysis and the test. For all three ground motions, the drifts obtained from the test and analyses are in phase although a small difference in the values of the drifts at different time expectedly exits between the two. During the first record, the maximum drifts obtained from the test and analyses are close to each other. For the subsequent two records, the maximum 
drift obtained from the test was larger than that from the analysis. This can be attributed to the carry-over effect in the test which had the effect of the previous records carried over to the subsequent records. On the other hand, the damage accumulated by the previous record was not taken over to the next analysis, and the next analysis started with no damage to the pier. Both in the test and analysis, EQ4 induced slightly more drift than EQ13 and the final record (i.e. EQ17) incurred serious damage. After $70 \mathrm{sec}$, both the test and analysis showed $8 \%$ drift, after which the analysis indicated numerical failure and the test was terminated due to imminent collapse.

\section{Conclusions}

This paper has proposed a systematic procedure for the identification of critical ground motions to be used in the seismic performance assessment of structures. Incremental Dynamic Analysis (IDA) is a useful means of pre-experiment analysis, as it confronts the thorny issue of aleotoric variability (i.e. record-to-record randomness). By using IDA, median and upper limit response expectations can be determined and the typical ground motions that would cause such response can be identified. Confidence bounds can thus be assigned to the experimental outcomes. The efficacy of the proposed ground motion selection methodology has been demonstrated via a dual computational-experimental investigation.

While the proposed procedure is particularly useful in destructive tests where the experimentalist often has only a single chance of conducting a meaningful experiment, there are still some unresolved issues, which, if solved, could significantly improve the efficiency of the process. Although PGA has been used as the intensity measure to generate IDA curves in this study, spectral acceleration would be a more efficient intensity measure. Using spectral acceleration as the intensity measure would give more confidence in the result or would require less number of records to generate results with the same level of confidence. 


\section{References}

1. ACI ITG/T1.1-99. Acceptance Criteria for Moment Frames Based on Structural Testing. ACI Provisional Standard, American Concrete Institute, 1999.

2. ATC24. Guidelines for Cyclic Seismic Testing of Components of Steel Structures. Applied Technology Council, California 1992; 57 pp.

3. Park R. Evaluation of ductility of structures assemblages from laboratory testing. Bulletin of the New Zealand Society of Earthquake Engineering 1989; 22(3):155-166.

4. Lukkunaprasit P, Thepmangkorn J. Load history effect on cyclic behaviour of reinforced concrete columns. ASCE Journal of Structural Engineering 2004; 130(10): 1629-1633.

5. Ingham JM, Liddell D, Davidson B. Influence of loading history on the response of a reinforced concrete beam. Bulletin of the New Zealand Society of Earthquake Engineering 2001; 34(2):107-124.

6. Takanashi K, Udagawa M, Seki M, Okada T, Tanaka H. Nonlinear earthquake response analysis of structures by a computer-actuator on-line system. Bulletin of Earthquake Resistant Structural Research Centre, University of Tokyo 1975, No. 8.

7. Mutsuyoshi H, Machida A, Tanzo W, Mashiko N. Inelastic seismic response of RC bridge pier using pseudodynamic test method. Transactions of the Japan Concrete Institute 1994; 16: 265-272.

8. Shing PB, Nakashima M, Bursi OS. Application of pseudodynamic test method to structural research. Earthquake Spectra 1996, 12(1): 29-56.

9. Iervolino I, Cornell CA. Record selection for nonlinear analysis of structures. Earthquake Spectra 2005, 21(3): 685-713.

10. Vamvatsikos D, Cornell CA. Applied incremental dynamic analysis. Earthquake Spectra 2004, 20(2): 523-553.

11. Yun SY, Hamburger RO, Cornell CA, Foutch DA. Seismic performance evaluation for steel moment frames. ASCE Journal of Structural Engineering 2002; 128(4): 534-545.

12. Cornell CA, Jalayer F, Hamburger RO, Foutch DA. Probabilistic basis for 2000 SAC Federal Emergency Management Agency steel moment frame guidelines. ASCE Journal of Structural Engineering 2002; 128(4): 526-533.

13. FEMA. Recommended seismic evaluation and upgrade criteria for existing welded steel moment frame buildings. Report No. FEMA-351, SAC Joint Venture, Federal Emergency Management Agency, Washington DC, 2000.

14. NZS3101-95. Concrete Structures Standard: NZS3101. Standards New Zealand: Wellington, 1995.

15. Carr AJ. RUAUMOKO: Inelastic Dynamic Computer Program. Department of Civil Engineering, University of Canterbury, Christchurch, New Zealand; 2004.

16. Shome N, Cornell CA, Bazurro P, Carballo JE. Earthquakes, records, and nonlinear responses. Earthquake Spectra 1998; 14(3): 469-500.

17. Mander JB, Basoz N. Seismic fragility curve theory for highway bridges in transportation lifeline loss estimation. Optimizing Post-Earthquake Lifeline System Reliability, TCLEE Monograph No. 16, 1999; 31-40.

18. Hayakawa R, Kawashima K, Watanabe G. Effect of bilateral loadings on the flexural strength and ductility of reinforced concrete bridge piers. Japan Society of Civil Engineers Journal of Earthquake Engineering 2003, 27:1-4 (in Japanese). 
Table 1 Collected seismic ground motion records

\begin{tabular}{|c|c|c|c|c|c|c|c|}
\hline No & Event & Year & Station & $\phi^{1}$ & $\mathrm{M}^{* 2}$ & $\begin{array}{c}\mathrm{R}^{* 3} \\
(\mathrm{~km})\end{array}$ & $\begin{array}{c}\text { PGA } \\
(\mathrm{g})\end{array}$ \\
\hline 1 & Loma Prieta & 1989 & Agnews State Hospital & 90 & 6.9 & 28.2 & 0.159 \\
\hline 2 & Imperial Valley & 1979 & Plaster City & 135 & 6.5 & 31.7 & 0.057 \\
\hline 3 & Loma Prieta & 1989 & Hollister Diff. Array & 255 & 6.9 & 25.8 & 0.279 \\
\hline 4 & Loma Prieta & 1989 & Anderson Dam & 270 & 6.9 & 21.4 & 0.244 \\
\hline 5 & Loma Prieta & 1989 & Coyote Lake Dam & 285 & 6.5 & 22.3 & 0.179 \\
\hline 6 & Imperial Valley & 1979 & Cucapah & 85 & 6.9 & 23.6 & 0.309 \\
\hline 7 & Loma Prieta & 1989 & Sunnyvale Colton Ave & 270 & 6.9 & 28.8 & 0.207 \\
\hline 8 & Imperial Valley & 1979 & El Centro Array \#13 & 140 & 6.5 & 21.9 & 0.117 \\
\hline 9 & Imperial Valley & 1979 & Westmoreland Fire Sta. & 90 & 6.5 & 15.1 & 0.074 \\
\hline 10 & Loma Prieta & 1989 & Hollister South \& Pine & 0 & 6.9 & 28.8 & 0.371 \\
\hline 11 & Loma Prieta & 1989 & Sunnyvale Colton Ave & 360 & 6.9 & 28.8 & 0.209 \\
\hline 12 & Superstition Hills & 1987 & Wildlife Liquefaction Array & 90 & 6.7 & 24.4 & 0.180 \\
\hline 13 & Imperial Valley & 1979 & Chihuahua & 282 & 6.5 & 28.7 & 0.254 \\
\hline 14 & Imperial Valley & 1979 & El Centro Array \#13 & 230 & 6.5 & 21.9 & 0.139 \\
\hline 15 & Imperial Valley & 1979 & Westmoreland Fire Sta. & 180 & 6.5 & 15.1 & 0.110 \\
\hline 16 & Loma Prieta & 1989 & WAHO & 0 & 6.9 & 16.9 & 0.370 \\
\hline 17 & Superstition Hills & 1987 & Wildlife Liquefaction Array & 360 & 6.7 & 24.4 & 0.200 \\
\hline 18 & Imperial Valley & 1979 & Plaster City & 45 & 6.5 & 31.7 & 0.042 \\
\hline 19 & Loma Prieta & 1989 & Hollister Diff. Array & 165 & 6.9 & 25.8 & 0.269 \\
\hline 20 & Loma Prieta & 1989 & WAHO & 90 & 6.9 & 16.9 & 0.638 \\
\hline
\end{tabular}

Component, ${ }^{2}$ Moment Magnitudes, ${ }^{3}$ Closest Distances to Fault Rupture

Source: PEER Strong Motion Database, http://peer.berkeley.edu/smcat/ 
Table 2 Classification of damage states in HAZUS [17]

\begin{tabular}{|lllll|}
\hline & Damage State & Failure Mechanism & Repair required & Outage \\
\hline DS1 & None & Pre-Yielding & None & No \\
DS2 & Minor/Slight & $\begin{array}{l}\text { Post-Yielding } \\
\text { Minor spalling }\end{array}$ & $\begin{array}{l}\text { Inspect, Adjust, } \\
\text { Patch }\end{array}$ & $<3$ days \\
DS3 & Moderate & $\begin{array}{l}\text { Post Spalling, Bar } \\
\text { buckling }\end{array}$ & $\begin{array}{l}\text { Repair } \\
\text { components }\end{array}$ & $<3$ weeks \\
DS4 & Major/Extensive & $\begin{array}{l}\text { Degrading of strength, } \\
\text { Bar fracture }\end{array}$ & $\begin{array}{l}\text { Rebuild } \\
\text { components }\end{array}$ & $<3$ months \\
DS5 & Complete/Collapse & Collapse & Rebuild structure & $>3$ month \\
\hline
\end{tabular}




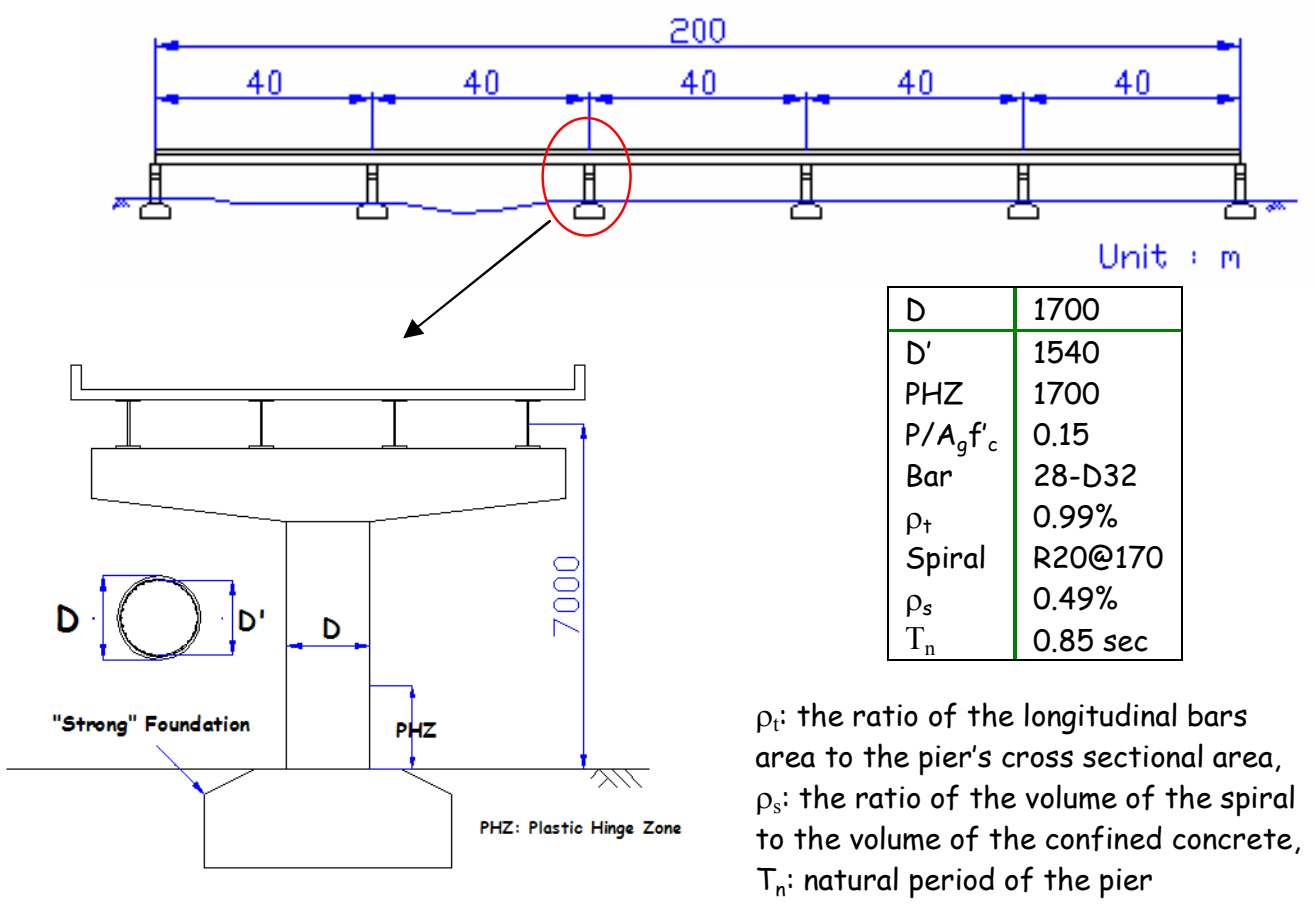

Figure 1 Features of the prototype bridge and the pier 

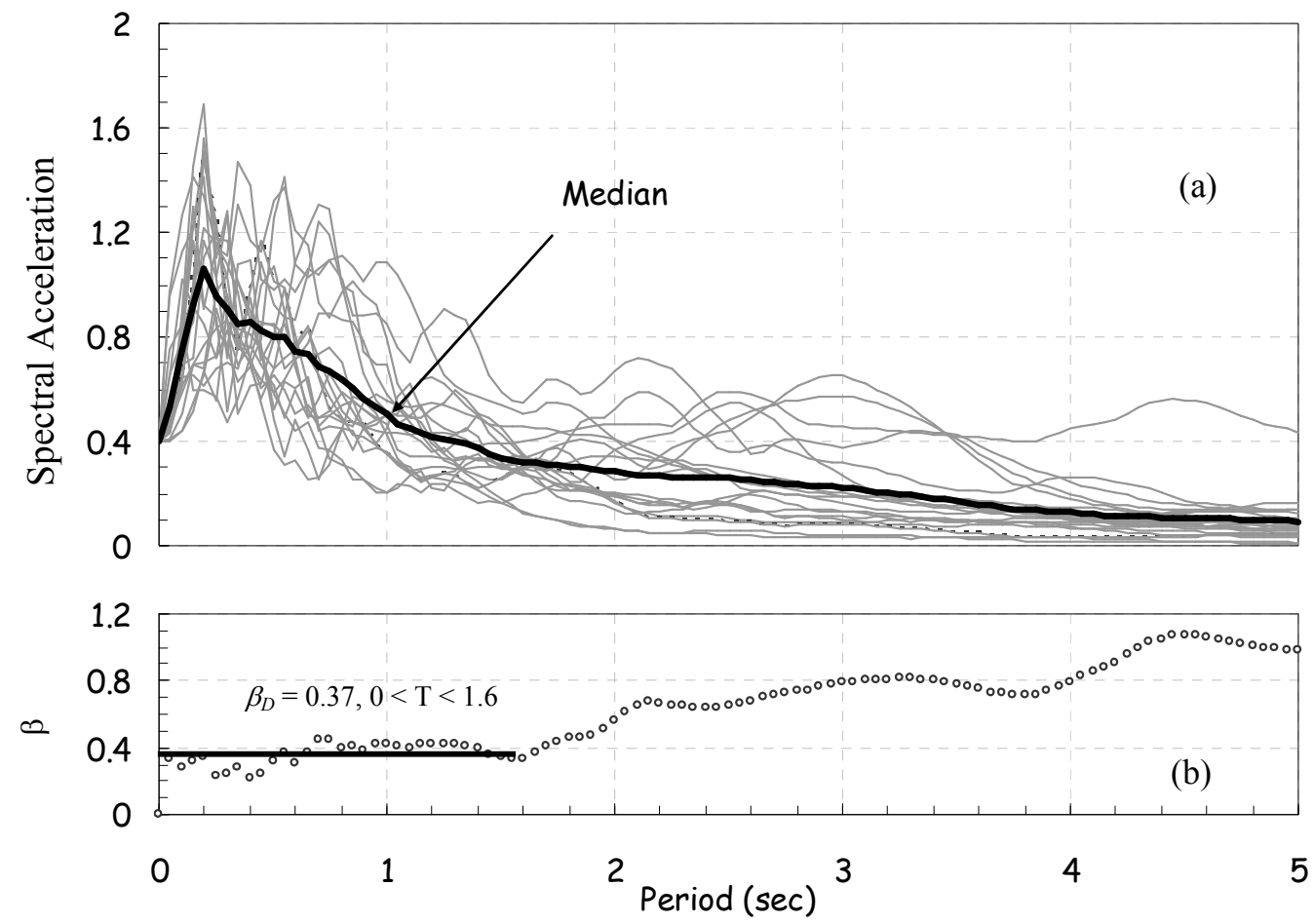

Figure 2 Selection of ground motion records normalised $\mathrm{PGA}=0.4 \mathrm{~g}$ 


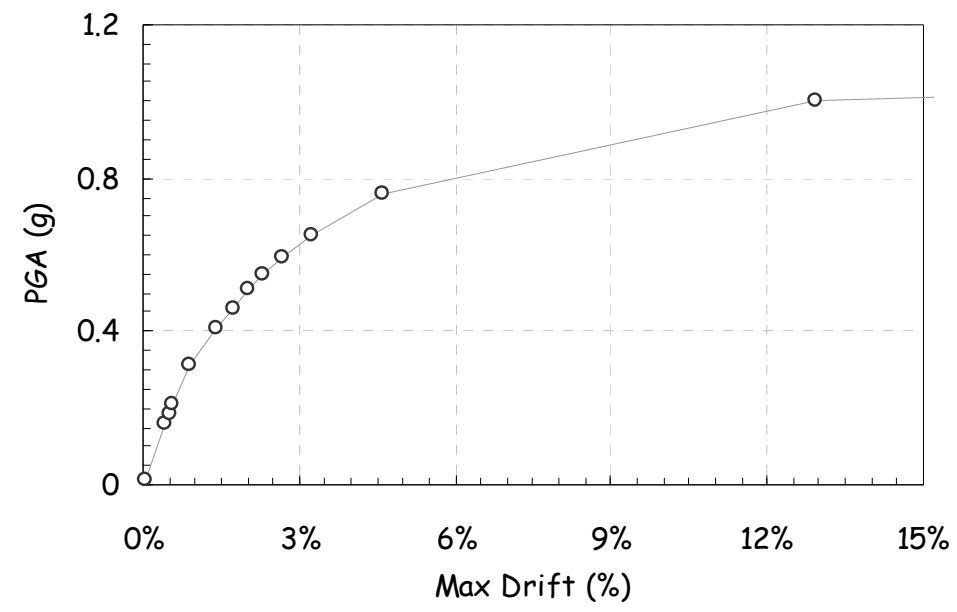

(a) Generation of an Intensity Measure (PGA) vs. engineering demand parameter (maximum drift) curve for one earthquake record

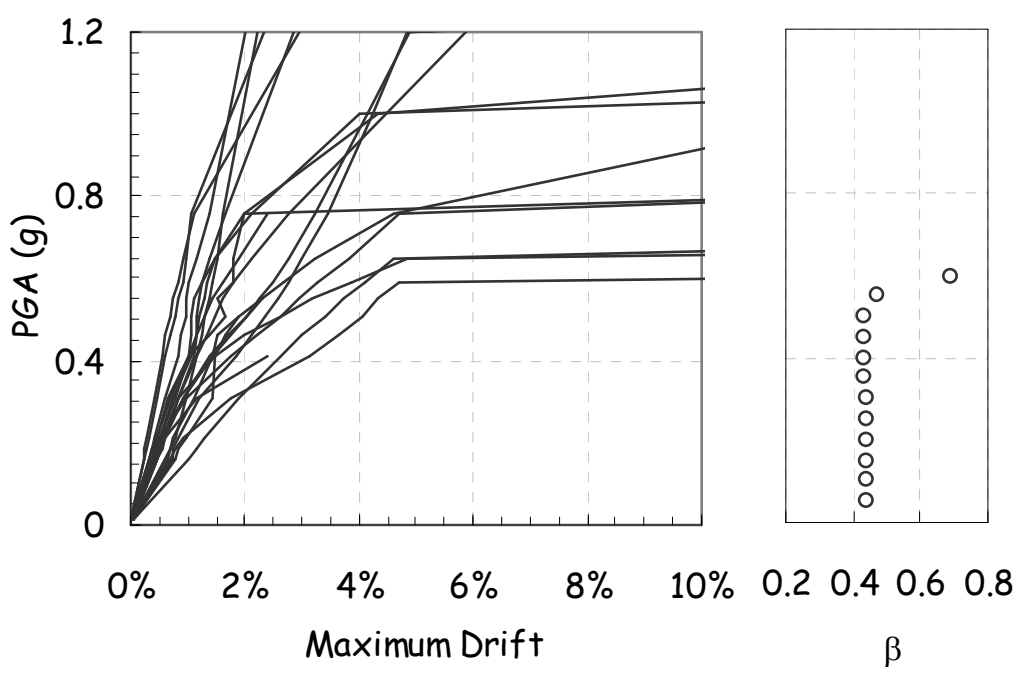

(b) IDA curve Ensemble for the 20 earthquake records

Figure 3 Results of Incremental Dynamic Analysis (IDA) 


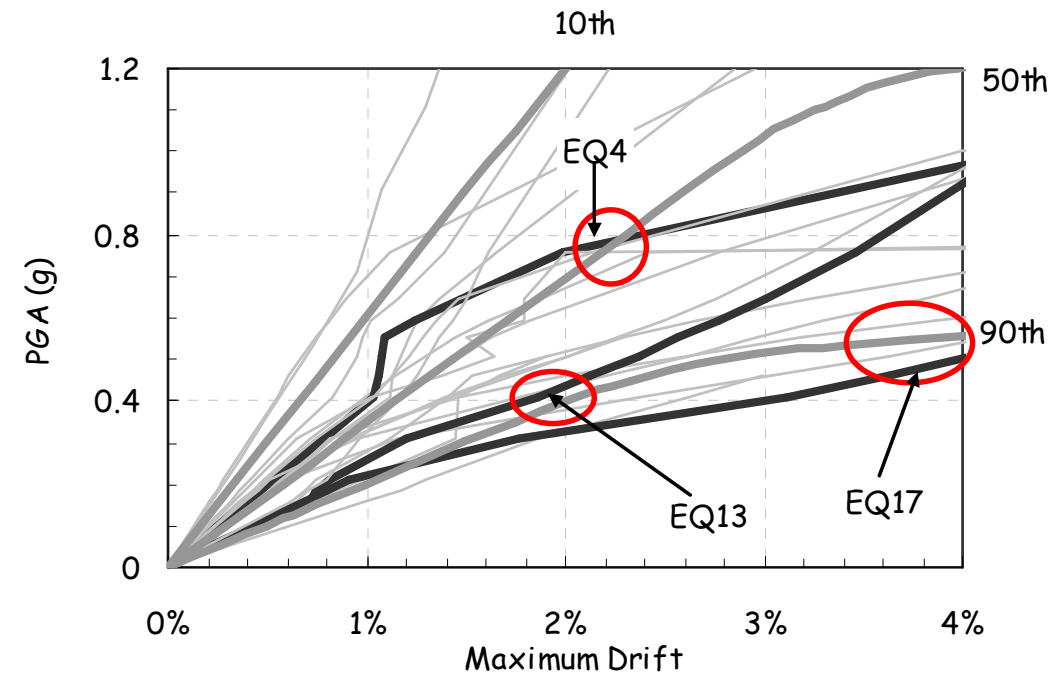

(a) Generation of the fractile IDA curves
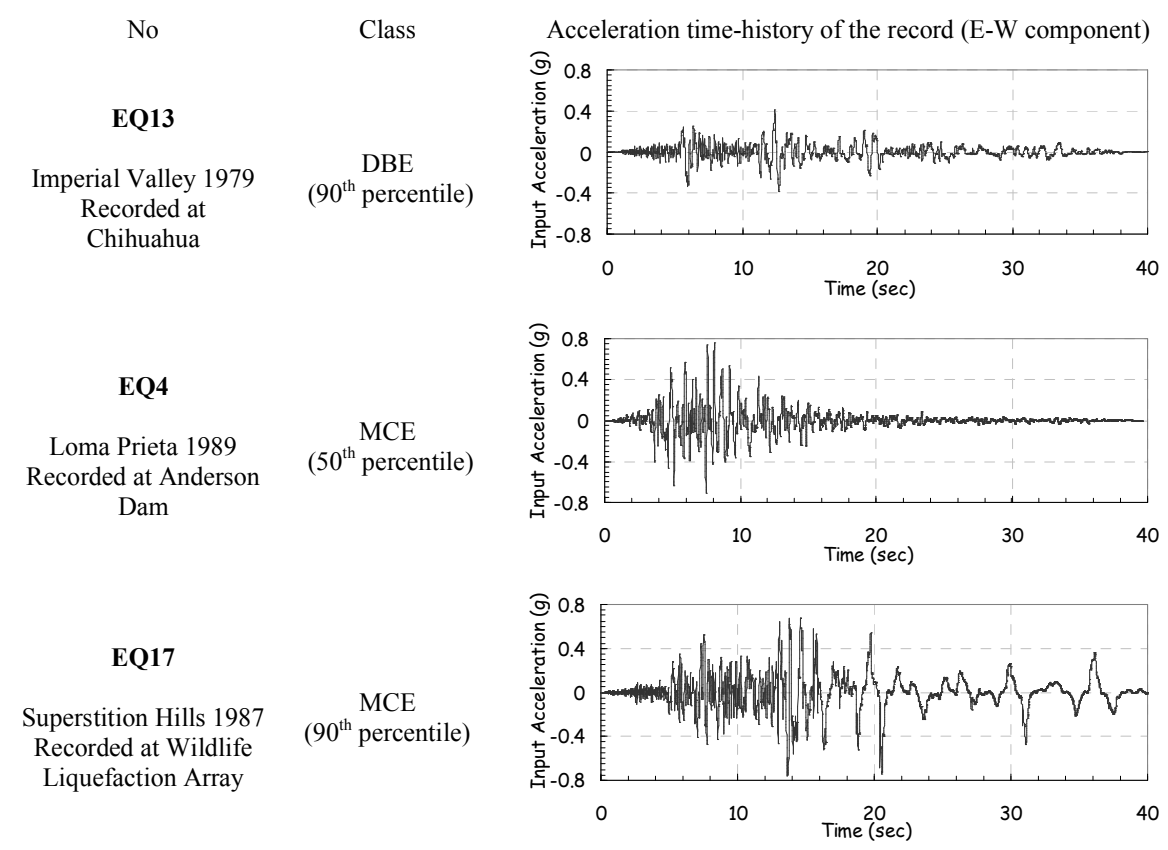

(b) Ground motions identified as DBE and MCE

Figure 4 Selection of the critical ground motions from the IDA curves 


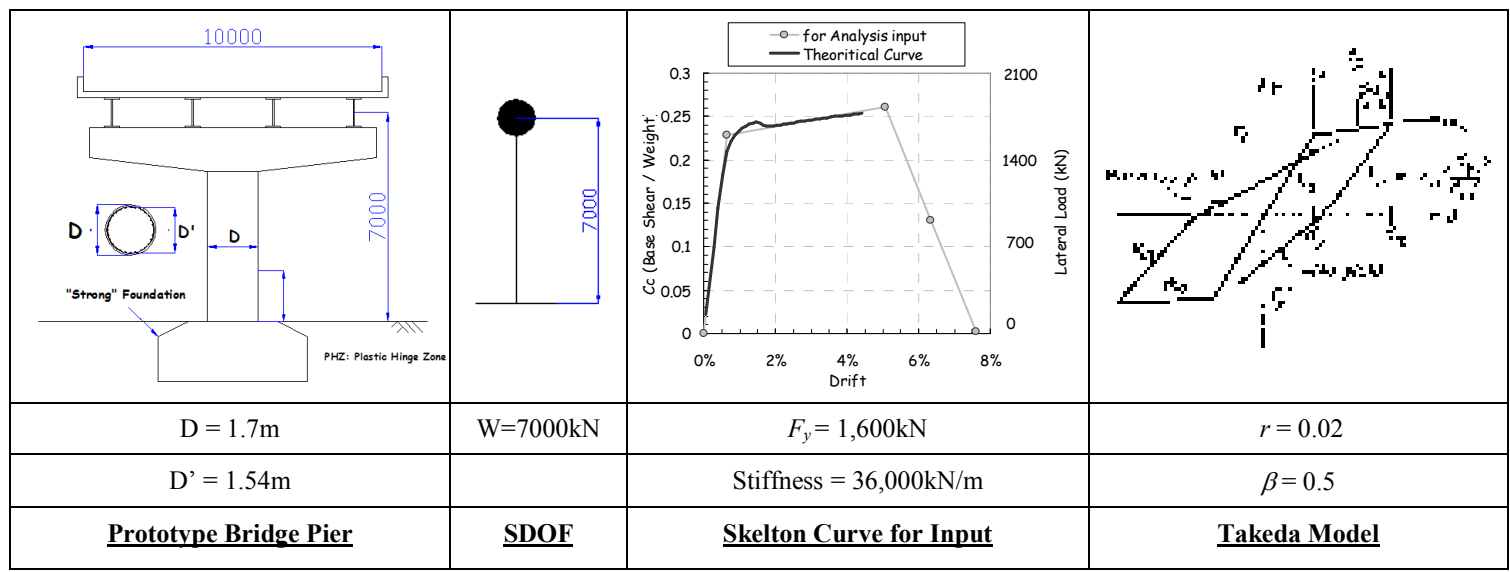

(a) Computational modelling for time history analysis
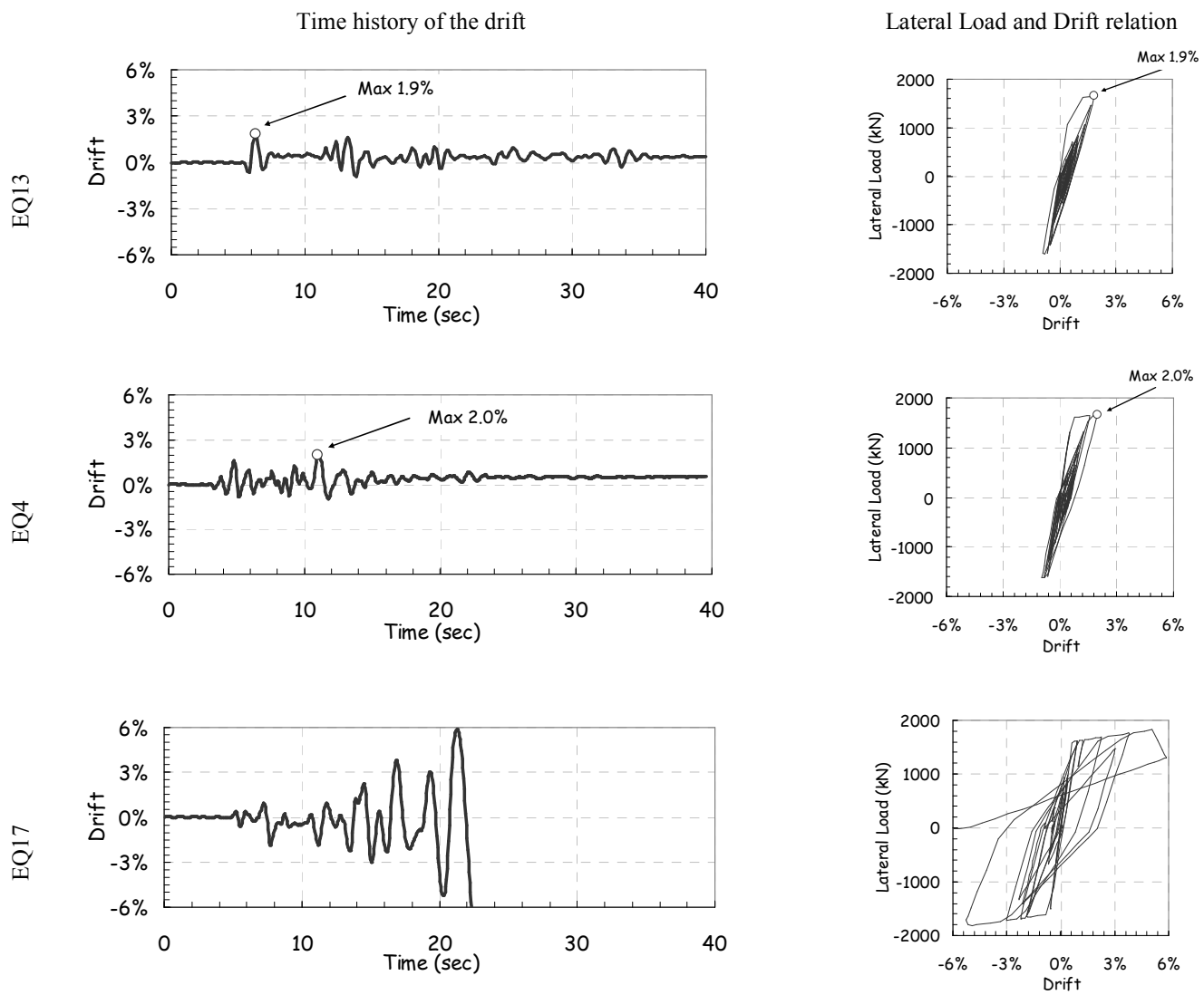

(b) Results predicted by time-history dynamic analysis

Figure 5 Results of the dynamic analyses of the pier using the selected ground motions 


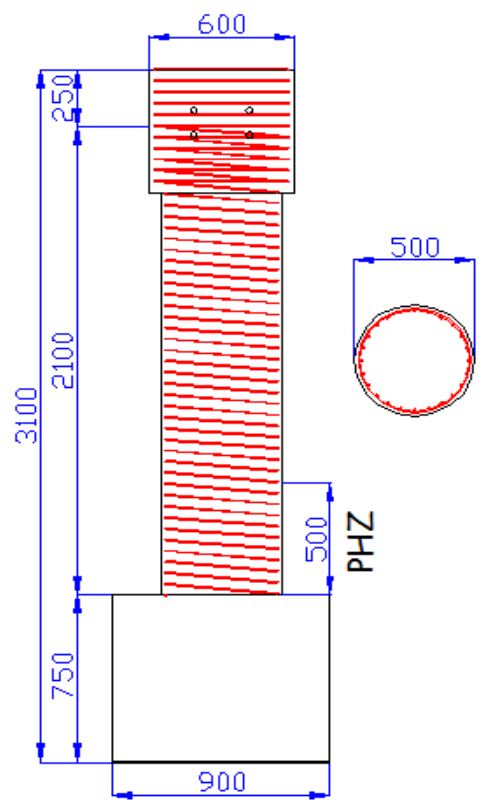

Details of the test specimen

\begin{tabular}{|l|l|l|l|}
\hline Diameter & $D$ & $\mathrm{~mm}$ & 500 \\
Gravity Load & $\mathrm{P}$ & $\mathrm{kN}$ & 630 \\
Longitudinal reinforcing bars & & & $24-\mathrm{D} 10$ \\
Longitudinal steel volume & $\rho_{+}$ & $\%$ & 0.96 \\
Spirals in PHZ & & & R6@50 \\
Spiral steel volume & $\rho_{s}$ & $\%$ & 0.51 \\
Concrete measured strength & $\mathrm{f}_{c}^{\prime}$ & $\mathrm{MPa}$ & 41.2 \\
Longitudinal steel: yield strength & $\mathrm{f}_{\mathrm{y}}$ & $\mathrm{MPa}$ & 539 \\
ultimate tensile strength & $\mathrm{f}_{\text {su }}$ & $\mathrm{MPa}$ & 677 \\
strain hardening & $\varepsilon_{\text {sh }}$ & $\%$ & 1.8 \\
strain at ultimate tensile strength & $\varepsilon_{\text {su }}$ & $\%$ & 14.6 \\
Spiral steel: yield strength & $\mathrm{f}_{y}$ & $\mathrm{MPa}$ & 461 \\
ultimate tensile strength & $\mathrm{f}_{\text {su }}$ & $\mathrm{MPa}$ & 633 \\
strain hardening & $\varepsilon_{\text {sh }}$ & $\%$ & 1.4 \\
strain at ultimate tensile strength & $\varepsilon_{\text {su }}$ & $\%$ & 19.6 \\
\hline
\end{tabular}

(a) $30 \%$ scaled model of the prototype bridge pier

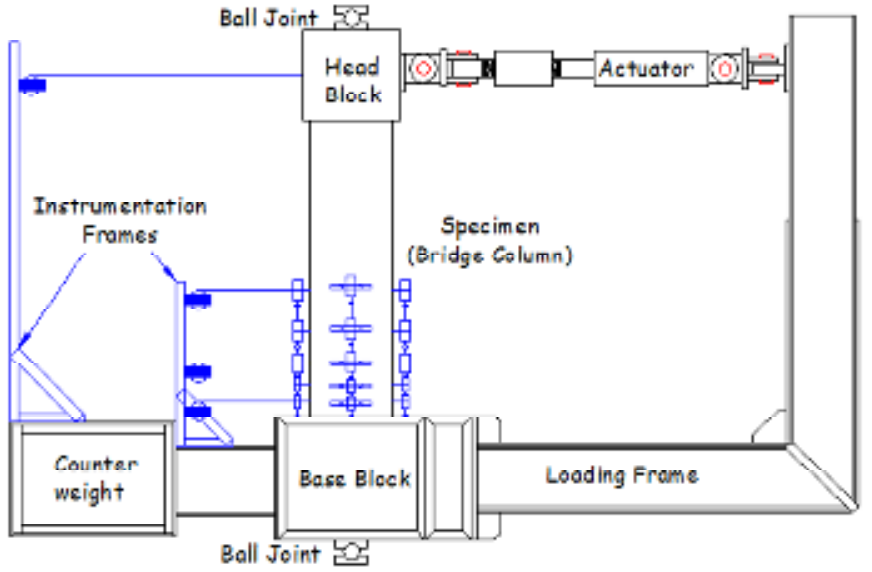

(b) Side elevation of the pseudodynamic test setup

Figure 6 Pseudodynamic test for seismic performance assessment of the pier 

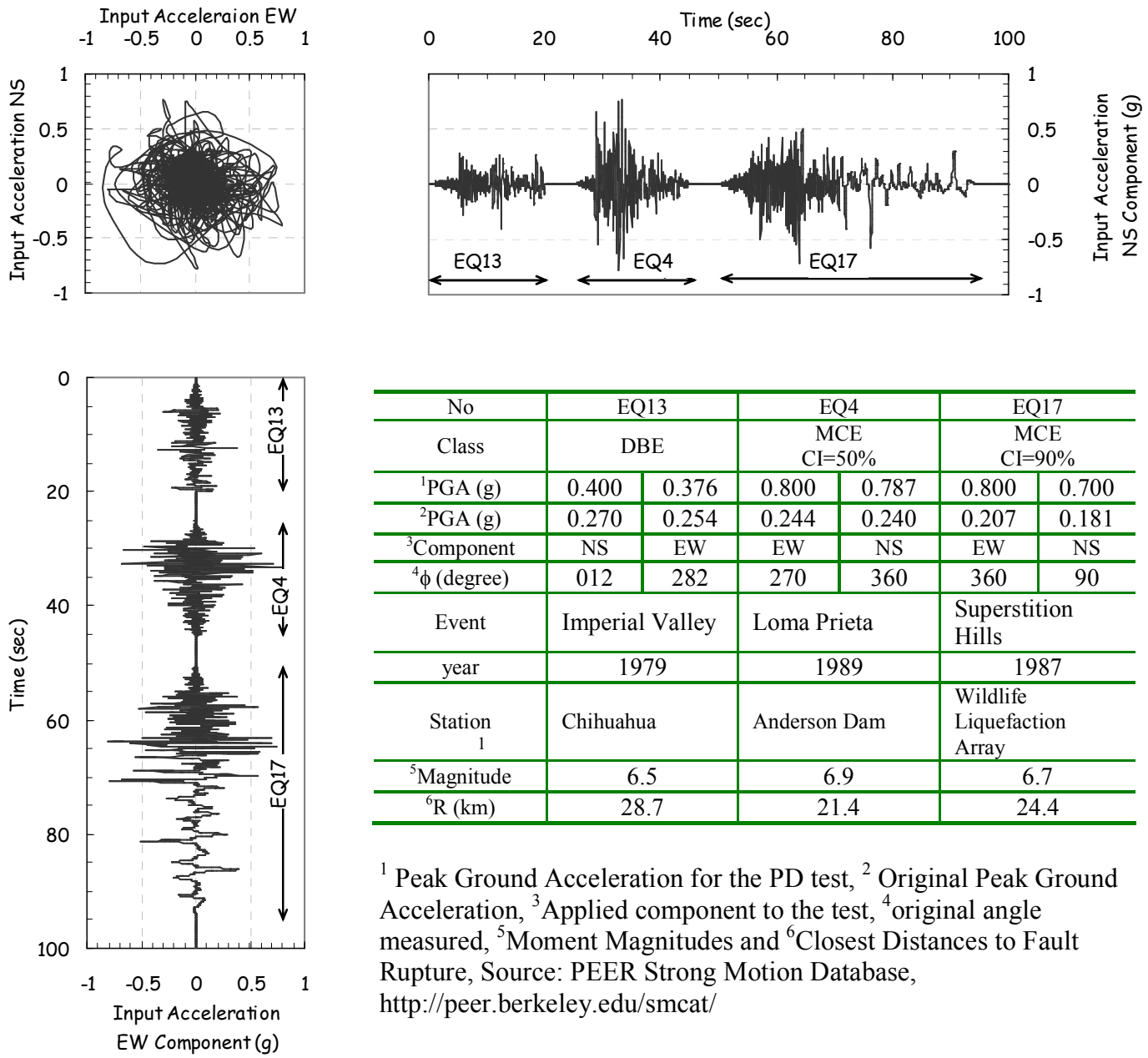

\begin{tabular}{|c|c|c|c|c|c|c|}
\hline No & \multicolumn{2}{|c|}{ EQ13 } & \multicolumn{2}{|c|}{ EQ4 } & \multicolumn{2}{|c|}{ EQ17 } \\
\hline Class & \multicolumn{2}{|c|}{ DBE } & \multicolumn{2}{|c|}{$\begin{array}{c}\text { MCE } \\
\text { CI }=50 \%\end{array}$} & \multicolumn{2}{|c|}{$\begin{array}{c}\mathrm{MCE} \\
\mathrm{CI}=90 \%\end{array}$} \\
\hline${ }^{1}$ PGA (g) & 0.400 & 0.376 & 0.800 & 0.787 & 0.800 & 0.700 \\
\hline${ }^{2}$ PGA (g) & 0.270 & 0.254 & 0.244 & 0.240 & 0.207 & 0.181 \\
\hline Component & NS & EW & EW & NS & EW & NS \\
\hline${ }^{4} \phi$ (degree) & 012 & 282 & 270 & 360 & 360 & 90 \\
\hline Event & \multicolumn{2}{|c|}{ Imperial Valley } & \multicolumn{2}{|c|}{ Loma Prieta } & \multicolumn{2}{|c|}{$\begin{array}{l}\text { Superstition } \\
\text { Hills }\end{array}$} \\
\hline year & \multicolumn{2}{|c|}{1979} & \multicolumn{2}{|c|}{1989} & \multicolumn{2}{|c|}{1987} \\
\hline $\begin{array}{c}\text { Station } \\
1 \\
\end{array}$ & \multicolumn{2}{|c|}{ Chihuahua } & \multicolumn{2}{|c|}{ Anderson Dam } & \multicolumn{2}{|c|}{$\begin{array}{l}\text { Wildlife } \\
\text { Liquefaction } \\
\text { Array }\end{array}$} \\
\hline${ }^{5}$ Magnitude & \multicolumn{2}{|c|}{6.5} & \multicolumn{2}{|c|}{6.9} & \multicolumn{2}{|c|}{6.7} \\
\hline${ }^{6} \mathrm{R}(\mathrm{km})$ & \multicolumn{2}{|c|}{28.7} & \multicolumn{2}{|c|}{21.4} & \multicolumn{2}{|c|}{24.4} \\
\hline
\end{tabular}

${ }^{1}$ Peak Ground Acceleration for the PD test, ${ }^{2}$ Original Peak Ground Acceleration, ${ }^{3}$ Applied component to the test, ${ }^{4}$ original angle measured, ${ }^{5}$ Moment Magnitudes and ${ }^{6}$ Closest Distances to Fault Rupture, Source: PEER Strong Motion Database, http://peer.berkeley.edu/smcat/

Figure 7 Detail of ground motion records used in the pseudodynamic test 

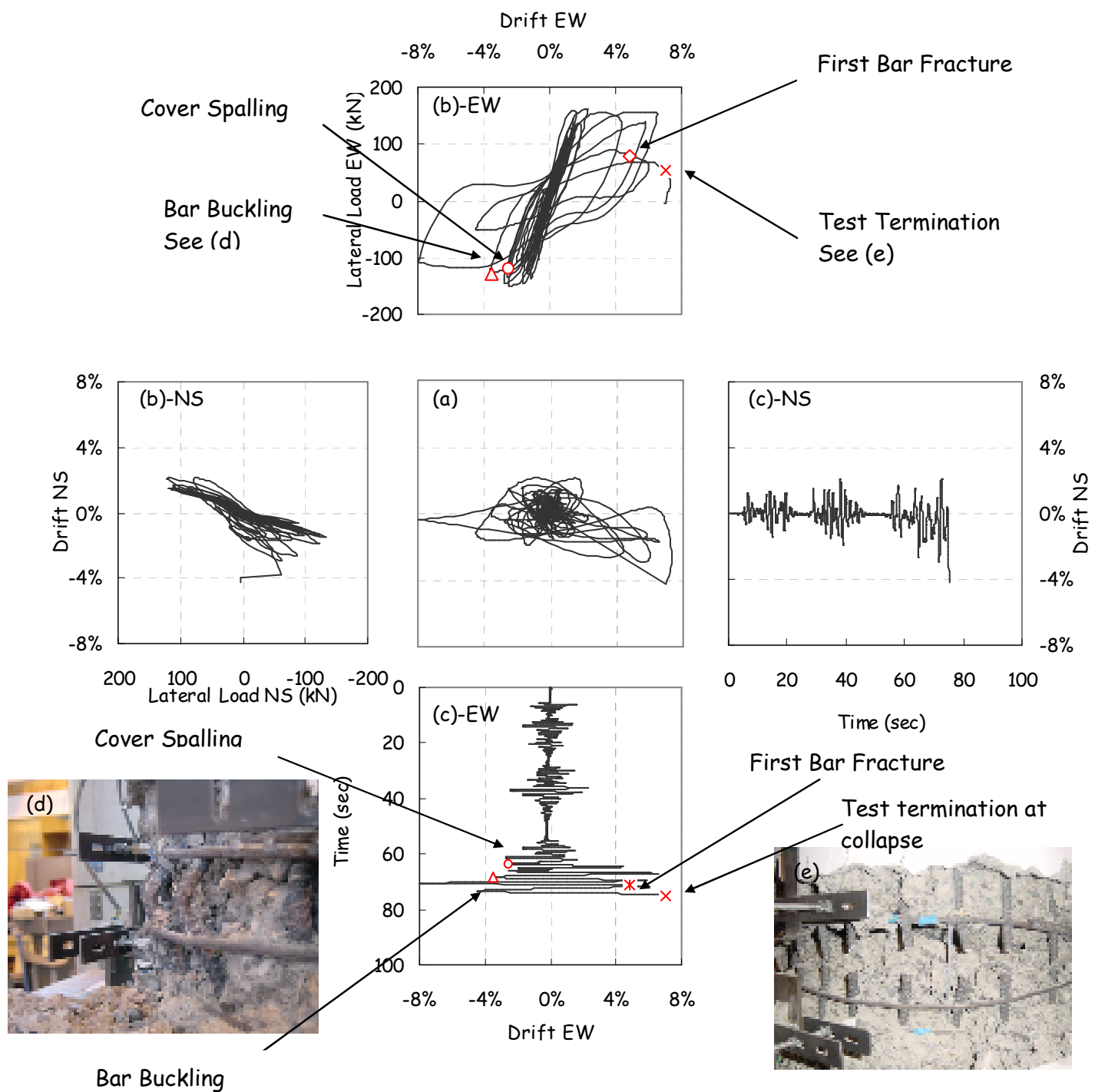

Figure 8 Experimental results (a) Plan view of the bi-directional drift orbit; (b) Loaddisplacement curve; (c) Time-history of the drift; (d) Photograph showing bar buckling at a drift of 3.6\%; and (e) photograph at the end of the test showing fracture of longitudinal bar due to low cycle fatigue. 


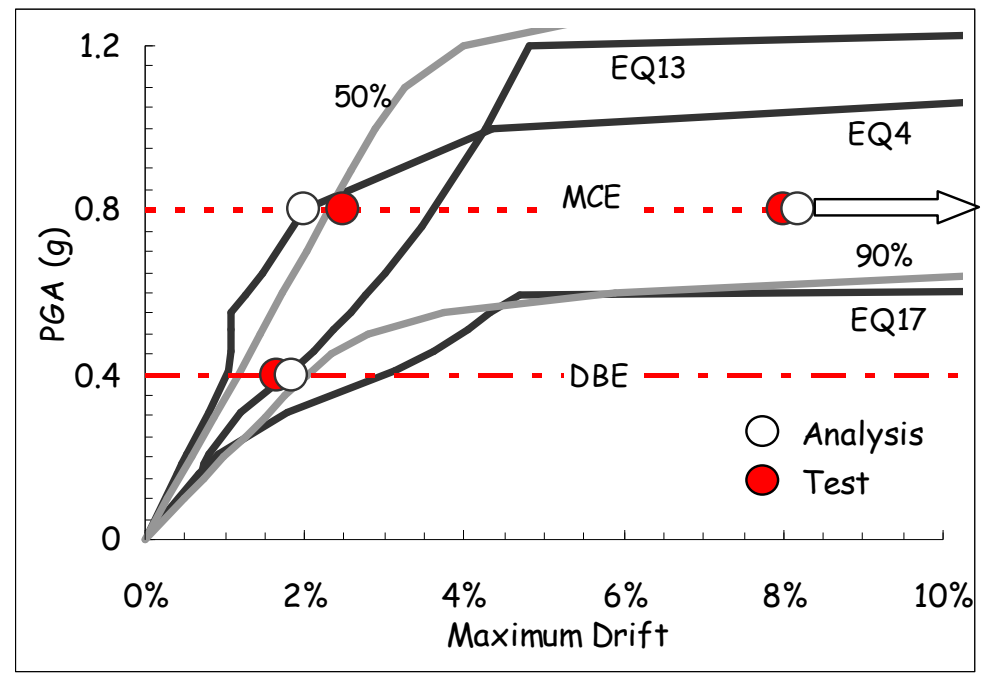

Figure 9 Results of pseudodynamic test using the identified ground motions plotted with the IDA curves 

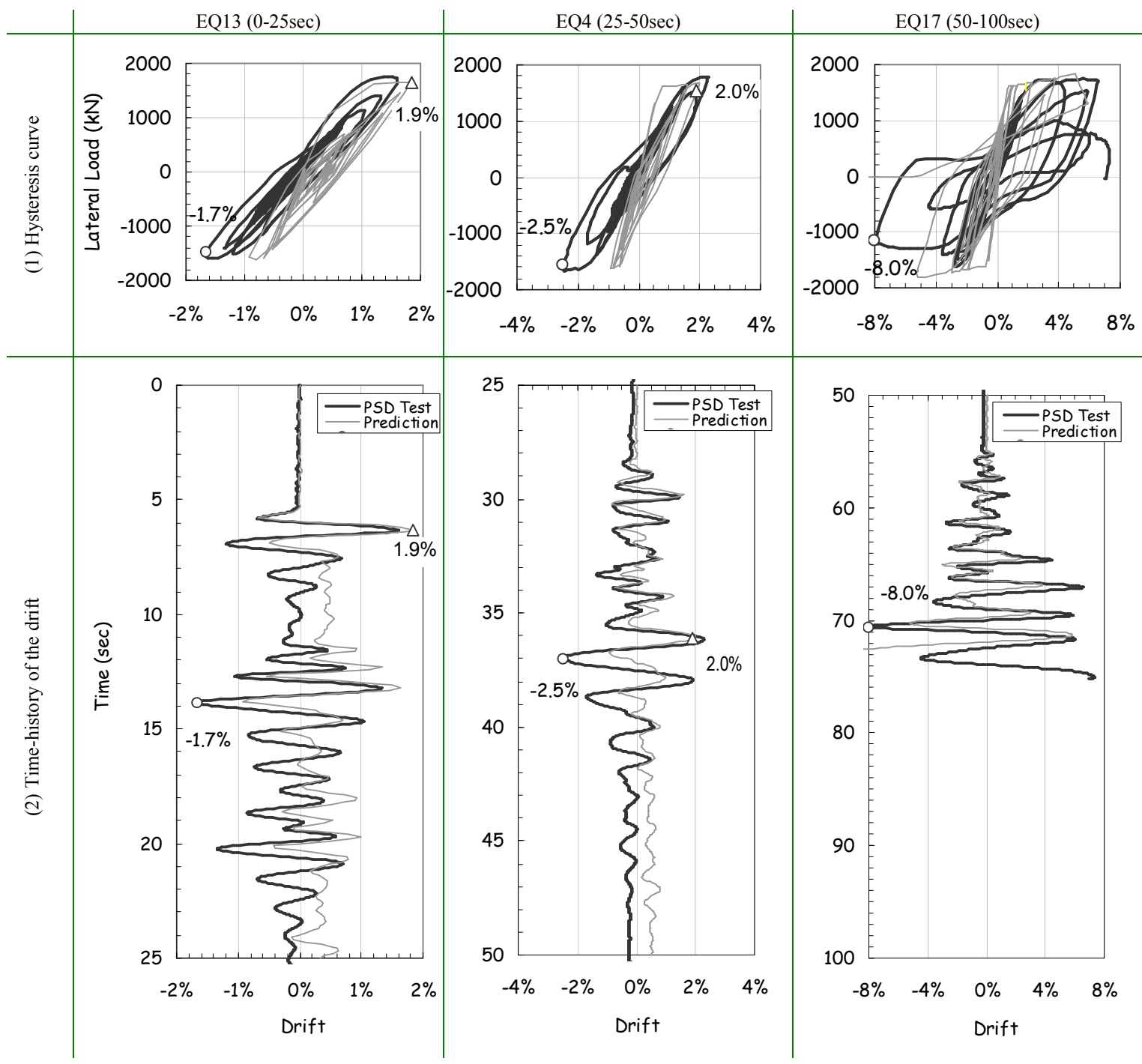

Figure 10 Comparison of the pseudodynamic test results with the analytical predictions 